\title{
Lexical and Contextual Variability of Idiomatic Phrasal Verbs in Harry Potter and the Deathly Hallows Movies
}

\author{
Hairus Salikin \& Ghofar Romli \\ English Department, Faculty of Letters, Jember University \\ (hairussalikin@gmail.com)
}

\begin{abstract}
The popularity of Harry Potter and the Deathly Hallows (HPDH) as a novel is almost accentuated in the movie version. However, the fascination of watching the movies may be interrupted by the problems arising from the use of some problematic expressions in the original language, especially idiomatic phrasal verbs (IPVs). This paper undergoes some procedures of the analysis starting from the process of data collection, progressing to selection, filtering, and labeling. It extracts PVs in HPDH (97 in HPDH part one and 70 in part two) using linguistic concepts of PV. Later by limiting the PVs under conventional and characteristics modelling function of idioms, IPVs can be identified and served as the primary data. The final phase of the analysis wants to see how lexical interpretation, relying on Oxford Advanced Learner's Dictionary $8^{\text {th }}$ Edition (OALD $8^{\text {th }} \mathrm{ed}$ ), and Halidayan contextual variability (field, tenor and mode) help classifying and explaining the meanings of the IPVs. Finally it is expected that this paper can offer appropriate logical and contextual interpretations of the IPVs. This way, by watching the HPDH, learners of English can gain better understanding of the movies and, more importantly, better knowledge of IPVs as inseparable part of their competence of EFL.
\end{abstract}

Keywords: HPDH, IPVs, lexical interpretation, contextual variability, contextual interpretations

The Harry Potter (HP) film series is based on the novels by author J. K. Rowling with the main story HP's mission to overcome his enemy Lord Voldemort (LV). HPDH1 starts with Harry, Ron, and Hermione's mission to find and destroy LV's secret to immortality and in HBDH2 is completed with destroying LV's secret and discovering the significance of the three Deathly Hallows (DH) in an attempt to destroy LV. Hence, both HPDH1 (2010) and HPDH2 (2011) dialogues have many idiomatic expression such as idioms. For instance; I feel like I can spit fire, kept an eye on us on that mirror, etc.

Generally, an idiom is an expression which is fixed and it is recognized by native speakers and this is followed by the use of the language in metaphorical way (Wright, 199, p. 7; Wyatt, 2006, p. 4). Many idioms are colloquial, they are used in informal conversation rather than in writing or formal language (Wyatt, 2006, p. 4). One of the reasons idiomatic language is difficult to interpret is because it is the area of language closest to culture. The metaphors of one culture will be different from those of another (Wright, 1992, p. 7). The most commonly used definition of culture is context. Therefore, learner needs context to understand the possible meaning of idioms.

Moreover, many idioms in this movie are formed using PVs, a PV is a verb formed 
with particle(s) including three parts such as a verb and an adverb or preposition or both. Most PVs are formed from a small number of verbs (look, get, go, come, put and set) and a small number of particles (away, out, off, on, up and in) (Wyatt, 2006, p. 4; McCarthy and O'Dell, 2004, p. 6; Flower, 1998, p. 7). These PVs whose meaning are not lexical will be called as IPVs.

As the IPV s in this movie are spoken by teenagers and the mostly impacted readership are teenagers, so the IPVs will be suitable to be learned by students to help them enhance their English language mastery.

In this on going research, I analyze the meanings of IPVs based on the lexical interpretation and the process decides the best possible meaning of each IPV in accordance with the context of the sentence and context of situation in relation to the movie. The primary data are the written script from $w w w$. moviesubtitles.org based on the real dialogue on the movie. Following by collecting and selecting the significant utterances that are considered to PVs based on linguists theory about PVs. The PV utterances considered to be IPVs are filtered using the OALD 8th ed. For example, "Can't wait no time for cozy catch up" has the IPVs "catch up". the IPVs are labelled based on the kinds of each categories of the verbs either transitive or intransitive. I analyze the meaning of IPVs in the written script using lexical interpretation and decide the best possible meaning of each IPVs based on contextual variability of the idioms. Finally, I make logical assumptions that serve as the conclusion.

\section{Method}

The primary data in this research is the written scripts of HPDH movie taken from www.moviesubtitles.org. Those data are collected based on linguist theory about phrasal verbs. Then, in order to interpret the idiomatic phrasal verbs, this research also needs the other data used as the context of the sentence and the situation to strengthen his assumption or interpretation on idiomatic expressions. The data of this research is documentary data. Hence the data can be called as qualitative data.

To process data in this research, some steps are needed. The collection of phrasal verbs identified from the script are then filtered to result legitimate idiomatic phrasal verbs with the help of OALD. Next, the writer will give the interpretation of the idiomatic phrasal verbs based on the lexical interpretation and the contextual variability of the idiomatic phrasal verbs. It should give clearer description to the social context which later can be found and connected with the particular way in which meaning of the idiomatic phrasal verbs is understood. The finding is expected to ease the movie goers in understanding idiomatic phrasal verbs without bugging themselves with opening the idiomatic phrasal verbs dictionary

\section{Result and Discussion}

Lexical analysis and contextual interpretation of Idioms in DPDH1 and HPDH2

The following example shows the problems to interpret the meaning of idiom in HPDH1 dialogue using lexical interpretation. Learners will not have the fullest understanding of the story/text/sentence of the movie when they translate idiom lexically. For example, this primary data is taken from the dialogue in scene 01:06:06,164 to 01:06:21,606 ( $w w w$. moviesubtitles.org).

This conversation has an idiom in the sentence "It sets my teeth on edge" in order to make the description of Harry Potter more sensible. Simple analysis applies lexical interpretation with lexicogrammar analysis, the analysis should be "It" as a subject, "sets" as verb which refers "to put" or "to start", " $m y$ teeth" as a noun phrase and an object of verb that refers to Harry's teeth. "on edge" as prepositional phrase refers to the outside limit of an object such as steeply sloping riverbank or mountain side. If this example is translated using literal meaning or lexical interpretation, it should be 


$\begin{array}{ll}\text { Harry Potter }= & \begin{array}{l}\text { He wants something } \\ \text { that Gregorovitch used } \\ \text { to have. I do not know } \\ \text { what. But he wants it } \\ \text { desperately. As if his life } \\ \text { depended on it. }\end{array} \\ \text { Hermione }= & \begin{array}{l}\text { Don't, it's his comfort } \\ \text { zone }\end{array} \\ \text { Granger } & =\begin{array}{l}\text { It sets my teeth on edge, } \\ \text { Harry Potter }\end{array} \\ \text { What is he expecting to } & \text { hear?? Good news?" } \\ \text { Hermione }= & \begin{array}{l}\text { One can only hope not } \\ \text { to hear bad news. }\end{array}\end{array}$

"something puts Harry's teeth on the outside limit of an object as mountainside". However, the reality of the movie indicates nothing happened to Harry's teeth and the dialogue is not doing on the outside limit of an object such as steeply sloping riverbank or mountainside. Hence, the analysis should find other ways that may help finding possible meaning of this expression.

The idiom "it sets my teeth on edge" has verb + particle combination in "set" as verb and "on" as preposition. But after putting noun phrase "my teeth" as object of verb, and "on edge" as prepositional phrase, this expression becomes idiomatic because the meaning combination of Verb + Object + Prepositional Phrase does not meet the general logical assumption, as in the sentence "Bill puts the mountain in his back." It is impossible to put mountain in Bill's back, therefore the sentence is illogical. Another instance would be "John eats all of the buses on the street." All people know the buses are not supposed to be eaten. So the interpretation of the lexical meaning of the verb "eat" demands an object commonly referred to as "food". The quoted sentence from the movie above cannot be understood if one only uses lexical interpretation. Our attempt to grasp the meaning of "it sets my teeth on edge" also escapes the lexical interpretation. We can start from the possible meaning interpretation of the PV "set + object (my teeth) + on edge. From the perspective of linguistics theory about PVs, the category of this expression is similar with transitive separable PV because the object is between the verb and the preposition, according to OALD, the particle of this expression has idiomatic meaning in "on edge" which has the relation with "nervous". The following analysis is coming from contextual variability of the idioms based on the story of the movie.

As a discourse, the utterance of the character in the movie "HPDH part one" has what is named as context of situation, (Halliday \& Hasan, 1989, p. 10) state that the environment of a text consists of field, tenor and mode. The field refers to the subject matter of the utterance of the character and what it is all about, tenor means the participants and their statuses, and mode is the way that the message of the movie is delivered to the audience. These three categories are described clearly as follows.

Therefore, context of situation based on the environment of a text consisting of field, tenor and mode refers to "uncomfortable feeling of Harry Potter". As a result, the possible meaning of this idiomatic expression based on OALD is (nervous) also the context of situation (uncomfortable feeling of Harry Potter) should be "it makes me very nervous". Furthermore, based on the lexical components, this idiom is based on the form "set" as Verb + "myteeth" as NP + "on edge" as PP, this scheme is similar with idiom variation summarized by Langlotz (2006).

\section{Lexical analysis and Contextual Interpretation of the IPVs in HDPH1 and HDPH2}

In this movie, there are many IPVs commonly used in dialogue, the data I have found are 89 kinds of PVs including 18 PVs repeated both HPDH1 and HPDH2. PVs in HPDH1 uttered 97 and 70 in $\mathrm{HPDH} 2$, is based on PVs theory by linguists. After all process, the meaning(s) of intransitive PVs or IPVs can identify easily using OALD 8th ed, ex. Come on, catch up, go on, etc. But OALD $8^{\text {th }}$ ed will not helpful in analyzing separable transitive IPVs. For example, this primary data is taken from HPDH part two dialogue in scene 00:02:33,617 to 00:02:57,377 (www.moviesubtitles.org).

This dialogue has what is named as IPV in sentence "Muggles think these things keep evil away", in order to describe Luna's opinion about Muggle's thought. 
Table 1. Contextual Analysis of Idiom

\begin{tabular}{cl}
\hline Elements of Context & \multicolumn{1}{c}{ Descriptions of the Context of Situation } \\
\hline The field & $\begin{array}{l}\text { The story begins when Harry, Hermione and Ron arrive in the } \\
\text { forest of Dean. In short, they want to destroy the locket they have } \\
\text { stolen from ministry of magic, but to no avail. Then Harry wears } \\
\text { the locket and fells more angry, fearful and overall bad-tempered } \\
\text { than normal. }\end{array}$ \\
\hline & $\begin{array}{l}\text { There are two participants in this discussion. In this case, the } \\
\text { speaker is Harry Potter and the hearer is Hermione Granger, }\end{array}$ \\
& $\begin{array}{l}\text { Harry talks to Hermione about his feeling and asks help to find } \\
\text { and to do something. Hermione gets information about the effect } \\
\text { of wearing the locket. }\end{array}$ \\
\hline Monor & $\begin{array}{l}\text { The messages of this movie are delivered from Harry Potter as } \\
\text { speaker and Hermione Granger as the hearer. It tells the audiences } \\
\text { about some information such as any feeling of unpleasant distaste } \\
\text { of the speaker. }\end{array}$ \\
\hline
\end{tabular}

Luna Lovegood $=$ It's beautiful here.

Bill Weasley = It was our aunt's. We used to come here as kids. The Order uses it now as a safe house. What's left of us at least.

Luna Lovegood $=$ Muggles think these things keep evil away. But they're wrong.

Harry Potter $=$ I need to talk to the Goblin.

The category of this expression is transitive separable PVs because the object is between verb and adverb. According to OALD $8^{\text {th }}$ ed, the combination of verb "keep" refers to "save" and adverb "away" refers to "a great distance", is idiomatic because the meaning of the word "keep" is out of its original meaning and this expression uses "evil" as the object of the verb generally connects with "the Devil and with what is bad in the world". Therefore, the lexical interpretation analysis of "keep evil away" in this dialogue should be "save an evil in a great distance".

As a result, in accordance with context of the sentence (Muggles think these things keep evil away. But they're wrong) and the situation (at peaceful home), the possible meaning of this expression should be "distancing from danger". When all IPVs listed in Appendix 2 are analyzed using the first method only, that is using OALD as the primary reference, viewers of the movie will only find limited numbers of IPVs understandable. IPVs lexical analysis using OALD in this movie results only $27 \%$ of their meaning can be found relatively easily using OALD. One instance in the movie taken from HPDH1 scene "Zip me up, will you?" almost instantly understandable only by matching the lexical meaning of the PV "zip up" with the depiction of the situation in the movie showing the presence of "zipper". However, "zip up" may still carries contextual variability when we are presented with different context that may suggest the PV to denote "silent" of "keeping one's mouth closed". Still, this characteristics of such IPVs found in the movie are not common.

Having said this, the optimum understanding of IPVs in the movie as both medium of entertainment and learning English as foreign language may not be achieved. Thus, the understanding of the remaining $63 \%$ of the IPVs may damage the enjoyment and beneficial learning method of HPDH movie if we one rely on the use of OALD. It stresses the 
Table 2. Contextual Analysis of IPV

\begin{tabular}{cl}
\hline Elements of Context & \multicolumn{1}{c}{ Descriptions of the Context of Situation } \\
\hline The field & $\begin{array}{l}\text { The story begins when Harry, Luna and Bill stay at the peaceful } \\
\text { house. In short, Harry wants to meet Goblin to ask the other LV } \\
\text { secret of immortality. }\end{array}$ \\
\hline Tenor & $\begin{array}{l}\text { There are two participants in this discussion. In this case, the } \\
\text { speaker is Luna and the hearer is Harry, Bill and his sister. Luna } \\
\text { comments on Bill answer about safe house to describe her opinion } \\
\text { about Muggle's thought. }\end{array}$ \\
\hline Mode & $\begin{array}{l}\text { The messages of this movie tell the audiences they are stay at } \\
\text { peaceful house. }\end{array}$ \\
\hline
\end{tabular}

significance of contextual variability of idioms, most notably, IPVs that leads us to using the contextual analysis to achieve optimum understanding.

\section{Conclusion}

Based on analysis above, the following conclusion can be presented that lexical interpretation helps easily in analyzing intransitive PVs but not the IPVs, more specifically, those of transitive separable IPVs. IPVs need context of situation to create possible meaning and general logical assumption in the dialogue including the field of IPVs is about the story of movie. The tenor means who take apart or the participants and the mode of IPVs in the movie is the message from movie to the audiences.

As a means of communication the languages of the characters in the movie HPDH should be treated as subjects of learning mostly because the viewers of the movies are potentially learners of English having minimum competence in the contextual variability of English idioms. The more understanding of the idioms taking the PV forms may offer new knowledge to the learners. So it is considerably important to infuse such understanding to the minds of younger learners of English to foster the use of multi-modal objects like movies to enhance their competence in understanding and practicing English as a foreign language.

\section{References}

Flower, J. (1998). Phrasal Verbs Organiser. London: Commercial Colour Press

Halliday, M.A.K. and Hasan, R. (1989). Language, Context, and Text: Aspects of Language in a Social-Semiotic Perspective. Oxford: Oxford University Press.

Langlotz, A. (2006). Idiomatic Creativity: A cognitive-linguistic model of idiomrepresentation and idiom-variation in English. Amsterdam: John Benjamins Publishing Company.

McCarthy, M. and O'dell, F. (2004). English Phrasal Verbs in Use. Cambridge: Cambridge University Press.

Wyatt, R. (2006). Check Your English Vocabulary for Phrasal Verbs and Idioms. London: A \& C Black Publishers Ltd.

www.moviesubtitles.org (2010). Harry Potter and Deathly Hallows Part 1.DVDScr. en.srt. Available at http://www. moviesubtitles.org/subtitle-62331.html.

www.moviesubtitles.org (2011). Harry Potter And Deathly Hallows Part 2.TS.TA.en.srt. Available at http://www.moviesubtitles. org/subtitle-63965.html. 


\section{Appendix}

Appendix 1. Idioms found in HPDH1 and HPDH2

\begin{tabular}{|c|c|}
\hline HPDH1 & $\mathrm{HPDH} 2$ \\
\hline $\begin{array}{l}\text { It sets my teeth on edge, what's he expecting } \\
\text { to hear? }\end{array}$ & Students out of bed! Students out of bed! \\
\hline $\begin{array}{l}\text { Mundungus, stick tight to me. I want to } \\
\text { keep an eye on you }\end{array}$ & ...you'll put your faith in me. \\
\hline We have to get the hell out of here. & Hold the fort, Neville. \\
\hline Bill takes his steak on the raw side now & $\begin{array}{l}\text { Hey Dean, on second thoughts, tell Profes- } \\
\text { sor ... }\end{array}$ \\
\hline Let me tell you. stop to freak out a bit. & $\begin{array}{l}\text { Get inside! This way! Take cover! Take } \\
\text { cover }\end{array}$ \\
\hline $\begin{array}{l}\text { If you've got something to say, don't be shy. } \\
\text { Spit it out. }\end{array}$ & I feel like I can spit fire! \\
\hline $\begin{array}{l}\text { All right, I'll spit it out. But don't expect me } \\
\text { to be grateful... }\end{array}$ & We plan, we get there, All hell breaks loose. \\
\hline \multirow[t]{2}{*}{ If I brought my parents back here now } & Kept an eye on us on that mirror. \\
\hline & They've set the bloody place on fire! \\
\hline
\end{tabular}

\section{Appendix 2. Separable IPVs found in HPDH1 and HPDH2}

\begin{tabular}{ll}
\hline \multicolumn{1}{c}{ HPDH1 } & \multicolumn{1}{c}{ HPDH2 } \\
$\begin{array}{ll}\text { Well fancy this , you are not you so shove it } \\
\text { up and strip }\end{array}$ & Muggles think these things keep evil away. \\
\hline Zip me up, will you? & $\begin{array}{l}\text { I said I'll get you in, I didn't say anything } \\
\text { about getting you out. }\end{array}$ \\
\hline He is just too polite to point it out. & We've got to plan, we've got to figure it out! \\
\hline We were going to bring it out. & If you get us past the guards into the vault... \\
\hline \multicolumn{1}{c}{ When you turned this place over } & $\begin{array}{l}\text { If she gives us away, we must swear to use } \\
\text { that sword to slit our own throats. }\end{array}$ \\
\hline Bleeding gave it away, didn't I? & $\begin{array}{l}\text { Get the word out to Remus and the others } \\
\text { that Harry is back. }\end{array}$ \\
\hline She says she would lock me up? & To blow it up! Boom! \\
\hline Bleeding give it away, didn't I? & I can bring it down. \\
\hline $\begin{array}{l}\text { Seems strange, mate. Dumbledore sends } \\
\text { you off }\end{array}$ & Take it...Take it up, please! \\
\hline Take it off! & \\
\hline I said, Take it off, now! & \\
\hline Take the Horcrux off. & \\
\hline Pick them up, Draco, now! Well well well ... & \\
\hline
\end{tabular}

